\title{
Matching global cobalt demand under different scenarios for co-production and mining attractiveness
}

\author{
Alexandre Tisserant ${ }^{1 *}$ and Stefan Pauliuk ${ }^{2}$
}

\section{*Correspondence:}

tisserant.alexandre@gmail.

com

${ }^{1}$ Industrial Ecology

Programme, Department

of Energy and Process

Engineering, Norwegian

University of Science

and Technology,

7491 Trondheim, Norway

Full list of author information

is available at the end of the article

\begin{abstract}
Many new and efficient technologies require 'critical metals' to function. These metals are often extracted as by-product of another metal, and their future supply is therefore dependent on mining developments of the host metal. Supply of critical metals can also be constrained because of political instability, discouraging mining policies, or trade restrictions. Scenario analyses of future metal supply that take these factors into account would provide policy makers with information about possible supply shortages. We provide a scenario analysis for demand and supply of cobalt, a potentially critical metal mainly used not only in high performance alloys but also in lithium-ion batteries and catalysts. Cobalt is mainly extracted as by-product of copper and nickel. A multiregional input-output (MRIO) model for 20 world regions and 163 commodities was built from the EXIOBASE v2.2.0 multiregional supply and use table with the commodity technology construct. This MRIO model was hybridized by disaggregating cobalt flows from the nonferrous metal sector. Future cobalt demand in different world regions from 2007 to 2050 was then estimated, assuming region- and sector-specific GDP growth, constant technology, and constant background import shares. A dynamic stock model of regional reserves for seven different types of copper, cobalt, and nickel resources, augmented with optimization-based region-specific mining capacity estimates, was used to determine future cobalt supply. The investment attractiveness index developed by the Fraser Institute specifically for mining industry entered the optimization routine as a measure of the regional attractiveness of mining.

The baseline scenario shows no cobalt supply constraints over the considered time period 2007-2050, and recovering about $60 \%$ of cobalt content of the copper and nickel ore flows would be sufficient to match global cobalt demand. When simulating a hypothetical sudden supply dropout in Africa during the period 2020-2035, we found that shortages in cobalt supply might occur in such scenarios.
\end{abstract}

Keywords: Cobalt, Copper, Nickel, Scenario analysis, Critical metals, Dynamic inputoutput analysis, Hybrid multiregional input-output model, Companion metals,

By-product

\section{Background}

Almost all elements of the periodic table are used in modern technology, especially for renewable energy and communication technologies. Graedel et al. assessed the

(c) 2016 Tisserant and Pauliuk. This article is distributed under the terms of the Creative Commons Attribution 4.0 International License (http://creativecommons.org/licenses/by/4.0/), which permits unrestricted use, distribution, and reproduction in any medium, provided you give appropriate credit to the original author(s) and the source, provide a link to the Creative Commons license, and indicate if changes were made. 
performance of potential substitutes for all major applications of the different elements (Greenfield and Graedel 2013). Their central finding is that no element can be completely replaced by others, making each element a unique and important contributor to modern technology.

These specialty metals may face supply constraints in the future, not just because of limited mineral resources, but also because of mismatch between demand and available production capacity (Gerling et al. 2004). Moreover, they may be subject to trade restrictions due to export limitations imposed by individual countries. As resources are getting depleted and ore grades decline, the costs of extracting a mineral will increase, though future scarcity is often not reflected in commodity prices at present (Prior et al. 2012). Regional resource scarcity, regional production capacity, regional policies, and international political relations strongly influence future availability and trade patterns for critical materials (European Commission 2010). To anticipate possible future development, one needs prospective assessment of the anthropogenic cycles of specialty metals (Pauliuk and Hertwich 2015), without attempting to predict the future. A scenario analysis of future supply of critical metals is a more modest and scientific approach than a prediction; it enables researchers and policy makers to study the consequences of future economic development on metal reserves and possible futures and supply shortages in different regions. Such a scenario analysis could provide the basis for dynamic assessment of material criticality, as proposed by (Roelich et al. 2014; Knoeri et al. 2013), by applying the criticality framework developed by (Graedel et al. 2012; Nuss et al. 2014) in a prospective model.

\subsection{Existing approaches to estimate future metal flows and resource depletion}

Estimating the time when current mineral resources will be depleted requires a scenario analysis of metal demand on the global scale and with a long-term perspective. While new for critical metals, this type of analysis is commonly applied to bulk materials including steel, cement, and aluminum. Some integrated assessment models (IAM), for example, consider energy-relevant bulk materials like steel and cement, but not critical materials. This can be seen from the 5th AR of the IPCC, where scenarios for GHG emissions from material production generated by IAMs are presented, but criticality aspects are not quantified (IPCC 2014).

Dynamic stock modeling and material flow analysis (MFA) can be combined to produce prospective studies of future global demand for bulk materials. It has been applied to steel (Hatayama et al. 2010; Pauliuk et al. 2013) and aluminum (Liu et al. 2012). The approach was refined to allow for the study of critical materials (Busch et al. 2014), but it has not yet been applied to potentially critical metals on the global scale. For specific sectors, especially electricity generation from renewable sources, prospective studies for total metal demand exist for silver, gallium, germanium, selenium, indium, tellurium, neodymium, and dysprosium (Zuser and Rechberger 2011; Elshkaki and Graedel 2013, 2014; Roelich et al. 2014; Løvik et al. 2015). These studies found potential supply shortages in different deployment scenarios for silver, tellurium, indium, and germanium.

Interconnections between host and by-product metals are increasingly recognized as a main component of criticality (Graedel et al. 2012; Frenzel et al. 2015; Peiró et al. 2013; Mudd et al. 2013b; Graedel and Reck 2015; Løvik et al. 2015). The previously mentioned 
MFA studies focused on quantifying flows of critical metals and potential imbalances between co-products of mining, but are lacking a clear link to models of total available resources and mining capacity. We believe that this link is of particular interest for critical metals, which are mainly extracted as by-product, because their future supply might still be bound to the mining developments of the host metal(s). Of particular concern are situations where new deposits enter production for their respective main metals, which contain no or insignificant amounts of the critical metal of interest.

Multiregional input-output analysis (MRIO) contains comprehensive information on international trade and it can be used to trace materials through the global supply chain, both in demand-driven (critical material footprint of final demand) and supply-driven models (distribution of critical materials across final products). Examples for the former include the study of neodymium, cobalt, and platinum footprint of Japanese households (Shigetomi et al. 2015) and for the latter they include the approach by Moran et al. (2014), who use a supply-driven model to trace a conflict mineral through the world economy. MRIO is suitable for making demand scenario analyses, because it contains 'recipes' based on coefficients denoting the amount of input required by unit of demand. From this information, product-specific demand scenarios and critical metal intensity of production scenarios can be created.

\subsection{Mining development}

The location and type of future mines of host metals will determine the supply of critical metals that are not mined as main product, because a new project for extraction of the host metal does not necessarily provide enough quantities of the companion metals to help match demand.

Factors that can influence the choice of where to expand capacities include ore grades, available infrastructure, environmental issues, relations with the local communities, political and social stability (Mudd et al. 2013b; Prior et al. 2012). These factors can be broadly divided into two categories: (1) the mineralogy of the deposit, which determines the grades, the recovery rate of by-product, and environmental issues. Cobalt recovery rates from by-products of copper and nickel mining can vary from 25 to $80 \%$ depending mostly on the type of deposit, while at the same time, potential mines where cobalt could be recovered as main product would rely on arsenic-rich ores and that would have to be managed carefully (Mudd et al. 2013b). (2) The location and surroundings of the deposit which include the accessibility, land ownership rights, and political stability. For cobalt, the Democratic Republic of the Congo has been the main supplier but its instability is known to have influenced cobalt price (Seddon 2001), and electricity shortages are known to influence the amount of cobalt refined in Congo (USGS 2014).

Future production of fossil fuels is usually modeled using 'ultimately recoverable resources' models, and a similar methodology has recently been applied to copper (Northey et al. 2014). The model by Northey et al. only takes into account the ore grade when deciding where to install new mining capacity. We believe that the attractiveness of the deposit location should also be taken into account. The Fraser Institute yearly publishes a survey of mining companies from which the Investment Attractiveness Index (IAI) is derived, which can be used to rank countries and jurisdictions. It has two components: (1) the Policy Perception Index that looks at policy factors influencing 
investments and (2) the Best Practices Mineral Potential Index that rates the pure attractiveness of the jurisdiction's geology (Cervantes et al. 2014).

\subsection{Research gap and goal}

There is a lack of prospective modeling tools to estimate future global demand for critical materials in different regions. Models to indicate how fast known resources may be depleted in different regions are available but the investment attractiveness of different regions has not been taken into account.

The goal of this work is to demonstrate the usefulness of IO-based techniques for quantifying the future flows of critical metals, and to combine IO with dynamic stock models to make it respect physical boundaries that are absent in standard Leontief IO modeling. We show how a static MRIO table can be used to estimate future critical material demand and develop an optimization routine to determine the location of new mines under geological and policy constrains.

\subsection{Scope}

This paper focuses on the global demand for and supply of cobalt, a potentially critical metal mainly used in high performance alloys but also in lithium-ion batteries and catalysts.

A hybrid MRIO model based on the EXIOBASE v2.2.0 multiregional supply and use table was built to estimate cobalt demand in different regions (Wood et al. 2014). Extraction of cobalt can happen in several regions of the world. To match supply and demand for cobalt, we apply an optimization routine that determines in which regions and in which mine types resources are extracted and where new mining capacity will be installed. To do justice to the by-product nature of cobalt $(\mathrm{Co})$ that is extracted from copper $(\mathrm{Cu})$ and nickel $(\mathrm{Ni})$ ore, we consider seven type of resources: one for each combinations of the three metals that can be present in a deposit at the same time $(\mathrm{Co}, \mathrm{Cu}$, $\mathrm{Ni}, \mathrm{Co}-\mathrm{Cu}, \mathrm{Co}-\mathrm{Ni}, \mathrm{Cu}-\mathrm{Ni}$ and $\mathrm{Co}-\mathrm{Cu}-\mathrm{Ni}$ ). This optimization model determines where the mining of cobalt is more likely to happen by considering regional mining capacity by mine and the IAI from the Fraser Institute to model mining risk.

The rest of the paper is structured as follows. Sect. 2 introduces the model approach and the data used. Sect. 3 presents the results for several scenarios. Sect. 4 discusses the findings and the model and Sect. 5 concludes.

\section{Methods}

Cobalt is used in many different applications and often in small quantities. To link future human development with cobalt demand one needs a model that allows us to trace the flows of cobalt through the entire world economy to link final consumption with resource demand. This task is commonly solved using multiregional input-output analysis (MRIO) (Miller and Blair 2009). Different MRIO models, including WIOD, Eora, and EXIOBASE are available (Tukker and Dietzenbacher 2013) and for the purpose of this study we need an MRIO model that contains detailed information about the metal industries. We chose EXIOBASE because it contains six different metal production sectors (cobalt is part of the 'other non-ferrous metal' sector) and seven different metal mining sectors, including separate sectors for copper and nickel ore mining. 
A general disadvantage of the MRIO approach when applied to critical materials is that tracing critical materials through IO tables requires gross assumptions about homogenous product mixes, as the aggregation level of $\mathrm{I} / \mathrm{O}$ is usually so high that it does not allow to distinguish specific critical metals from the bulk of nonferrous metals. The source of product inhomogeneity is twofold. First, final products cover a very wide spectrum of devices, which are aggregated into a few sectors. EXIOBASE2, for example, contains only nine types of manufactured goods (Wood et al. 2014). Second, the critical materials are commonly aggregated together into the non-ferrous metal sector, or to even higher levels. Disaggregation of individual metal sectors in IO tables, as shown by Hawkins et al. (2007), Nakamura et al. (2008), Nakajima et al. (2013), Ohno et al. (2014), has been done at the country level, but requires very detailed data that are usually not available for critical metals on the global scale. Moreover, MRIO tables represent oneyear snapshots of the world economy or short historic time series only, and there is no standard procedure for how to extrapolate these tables into the future.

The big advantage of tracing critical metals in MRIO tables is that the magnitude of their flows is usually much smaller than the magnitude of the aggregated nonferrous metal flows they are part of. In our case for example, the share of cobalt in the total output of other nonferrous metals is less than $2.6 \%{ }^{1}$ Hence, critical material flows can be considered as perturbation or extension of the nonferrous metal sectors, and instead of properly disaggregating the A-matrix, it is sufficient to hybridize it by adding the data on the physical cobalt requirements of the different cobalt-consuming sectors and to calibrate the hybridized model so that the figures for cobalt use for the reference year are met.

MRIO tables represent one-year snapshots of the world economy, and there is no standard procedure for how to extrapolate these tables into the future. Still, scenario development for A-matrices is common in the literature (Leontief and Duchin 1986; De Koning et al. 2015; Hertwich et al. 2015; Gibon et al. 2015). To build scenarios for future cobalt demand, we start with the calibrated hybridized model for 2007, and extrapolate it into the future by scaling up final demand according to existing scenarios for regional average GDP growth rates published by the OECD (2015). These are broken down by distributing the global growth rates into the different sectors using historic sector-specific income elasticities for the period 1995-2011. This procedure does not take into account substantial changes in technology, demand structure, and trade patterns, which can be expected for the future. It therefore only provides a rough indication of possible future cobalt demand. A similar pathway was taken by Nakamura et al. (2014), who assumed a constant use pattern of steel throughout the 21st century in absence of detailed steel usage scenarios. To compensate for the simplicity of our basic scenario assumptions, we perform a sensitivity analysis on the global economic growth rate and the copper intensity of the world economy, which directly impacts cobalt supply from copper mines.

To understand how the metal demand derived from our hybrid-MRIO model can be matched, a mining optimization routine is developed to determine in which region and from which deposit the extraction shall happen. It is based on linear programming and

${ }^{1}$ World refined cobalt production in 2007 was 53,300 tons at a metal price of $30.55 \$ / 1 \mathrm{~b}$ (49.2 $€ / \mathrm{kg}$ at 2007 rate)(USGS 2010). Total global supply of other nonferrous metals in EXIOBASE is $102796 \mathrm{M€}$. 
assumes that mine production should happen preferably in regions that are perceived as less risky by mining companies.

\subsection{Scenario development: economy, technology, and trade}

Table 1 gives an overview of the assumed development for economy, technology, trade, mining risk, cobalt intensity, and mining that are used to build the scenarios for cobalt demand and supply between 2007 and the year 2050. The different parameter changes are explained below.

Table 2 gives an overview of the scenarios we defined. Scenario 1 considers a regionspecific mining risk for determining mining output whereas this component is ignored in scenario 2. Both scenarios come in two versions, where cobalt is considered a byproduct and cobalt demand does not enter the optimization as constraint (a), and a version where $\mathrm{Cu}$ and $\mathrm{Ni}$ mining capacities are installed by taking Co supply into account.

\subsection{Details of model computation}

The model to link final demand for products and services to the depletion of cobalt resources consists of several parts (Fig. 1). Below, each step is explained in detail. For a full description of the methodology we refer to the Additional file 1.

\subsection{Step 1: Estimating future final demand across all sectors and regions}

Our simple scenario to project future cobalt demand is based on a final demand increase according to GDP growth projections. These projections were retrieved from the OECD until 2050 and aggregated if necessary following the regional aggregation of the MRIO model (OECD 2015). Some historical values of GDP were also retrieved from the World

\section{Table 1 Overview of scenario development}

\begin{tabular}{|c|c|}
\hline Economy & $\begin{array}{l}\text { Economic growth follows the baseline long-term GDP projection from the OECD. Scenario } 5 \\
\text { tests the sensitivity of growth on metal demand }\end{array}$ \\
\hline Technology & $\begin{array}{l}\text { A constant technology A-matrix is assumed } \\
\text { Scenario } 4 \text { tests the sensitivity of primary copper-intensity of the economy on cobalt supply. } \\
\text { Less copper mining could mean less cobalt extracted }\end{array}$ \\
\hline Trade & A constant trade pattern is assumed \\
\hline Mining risk & $\begin{array}{l}\text { Mining risk is region- and mine type-specific } \\
\text { Scenario } 2 \text { tests the sensitivity of mining risk on metal extraction, by setting it equal for all } \\
\text { regions and all mines } \\
\text { Scenario } 3 \text { assumes a drop-out of Africa in metal supply because of instability in the Republic } \\
\text { Democratic of the Congo, which supplies a significant share of the studied metals }\end{array}$ \\
\hline Cobalt intensity & Cobalt intensity of manufactured products remains the same as of 2007 \\
\hline Mining & $\begin{array}{l}\text { Constant regional and mine type-specific ore grades are assumed and correspond to deposit- } \\
\text { wide average for each mine type in each region } \\
\text { Mining capacity is increased endogenously }\end{array}$ \\
\hline Cut-off grade & $\begin{array}{l}\text { Cut-off grade, the minimum grade at which the metal can be economically extracted, is an } \\
\text { important parameter for the mining industry and gives the amount of metal that can be } \\
\text { extracted from the known reserves. Therefore, cut-off grade determines new refining capac- } \\
\text { ity (optimized for the given cut-off grade) and regional distribution of extractable resources, } \\
\text { which should be included into the model as capacity is bound to a given concentration of } \\
\text { metal in ore and global mining risk is bound to the new distribution of extractable resources. } \\
\text { The model, however, consider that each region have a constant ore grade for their resources, } \\
\text { since all identified deposits (under extraction or not) are aggregated to model one mine at } \\
\text { the regional level. It means that marginal mining capacity and production is bringing in line } \\
\text { at regional average ore grade }\end{array}$ \\
\hline
\end{tabular}


Table 2 Scenario definition for cobalt supply

\begin{tabular}{|c|c|c|}
\hline Number & Sub & Description \\
\hline \multirow[t]{2}{*}{1} & $\begin{array}{l}\text { a) Cobalt is only extracted as by-product (is not } \\
\text { included in the optimization routine) }\end{array}$ & \multirow[t]{2}{*}{ Mining risk is different in each regions } \\
\hline & $\begin{array}{l}\text { b) Cobalt needs to be supplied (is included in } \\
\text { optimization routine and global extraction of } \\
\text { cobalt shall equal global cobalt demand) }\end{array}$ & \\
\hline \multirow[t]{2}{*}{2} & $\begin{array}{l}\text { a) Cobalt is only extracted as by-product (is not } \\
\text { included in the optimization routine) }\end{array}$ & \multirow[t]{2}{*}{ Mining risk is the same in all regions } \\
\hline & $\begin{array}{l}\text { b) Cobalt needs to be supplied (is included in } \\
\text { optimization routine and global extraction of } \\
\text { cobalt shall equal global cobalt demand) }\end{array}$ & \\
\hline \multirow[t]{2}{*}{3} & $\begin{array}{l}\text { a) Cobalt is only extracted as by-product (is not } \\
\text { included in the optimization routine) }\end{array}$ & \multirow{2}{*}{$\begin{array}{l}\text { Mining risk in Row Africa is set to } 100 \text { during } \\
2020-2035 \text { and ramp-down of capacity from } \\
\text { capacity } 2020 \text { to } 5 \% \text { of capacity } 2020 \text { over } 2023 \\
\text { until } 2029 \text { and ramp-up back to } 80 \% \text { of } 2020 \\
\text { capacity in } 2035\end{array}$} \\
\hline & $\begin{array}{l}\text { b) Cobalt needs to be supplied (is included in } \\
\text { optimization routine and global extraction of } \\
\text { cobalt shall equal global cobalt demand) }\end{array}$ & \\
\hline \multirow[t]{2}{*}{4} & a) Copper demand is reduced by $20 \%$ in 2050 & \multirow{2}{*}{$\begin{array}{l}\text { Primary copper demand is modified in the } \mathrm{A} \\
\text { matrix (cobalt is considered by-product only and } \\
\text { mining risk differs in each regions) }\end{array}$} \\
\hline & b) Copper demand is increased by 20 \% in 2050 & \\
\hline \multirow[t]{2}{*}{5} & a) Growth rate is slowed down by $20 \%$ in 2050 & \multirow{2}{*}{$\begin{array}{l}\text { GDP growth is 'slowed down' or 'speed up' (cobalt } \\
\text { is considered by-product only and mining risk } \\
\text { differs in each regions) }\end{array}$} \\
\hline & b) Growth rate is speed up by $20 \%$ in 2050 & \\
\hline
\end{tabular}

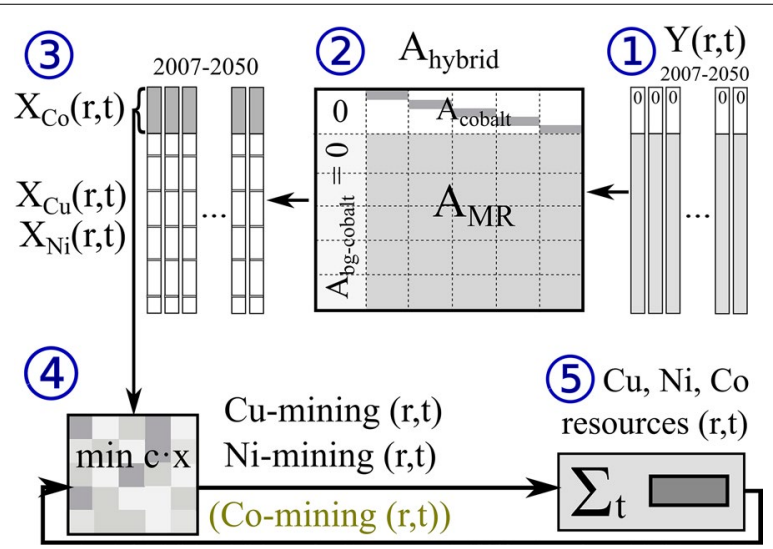

Fig. 1 Model structure. 1 Estimating future final demand by using exogenous GDP projections and breaking them down into sectors using historic growth rates for the spending in different sectors. 2 Hybridizing the 20 regions MRIO model to separate cobalt demand (physical foreground matrix $\mathrm{A}_{\text {cobalt }}$ ) from demand for nonferrous metals. 3 Determining the total demand of cobalt by region and year using the Leontief I/O model and assuming a constant A-matrix. 4 Solve a linear program to determine extraction patterns for $\mathrm{Cu}$, $\mathrm{Ni}$, and Co that are maximally attractive for investors. 5 Use a dynamic stock model of the known cobalt resources to determine their depletion over time

Bank (2015). Some countries/regions were not listed in the OECD dataset. Their GDP growth was assumed to be the same as the average growth of non-OECD countries.

Using the time series for multiregional final demand for the years 1995 and 2011 (EU DESIRE Project 2013), we determined historic sector-specific growth rates over these 16 years, which were used as proxy to determine future income elasticities to distribute the overall GDP growth in a country across the 163 sectors of the MRIO model (cf. section S1-1 in the Additional file 1). 
We believe that keeping a product-specific growth rate is better than growing demand only with GDP growth, because some sectors grow faster than others as countries get richer and this impacts metal demand. At the same time, it is hard to say which demand for products will grow more or less, because of not only new technology but also lifestyle and 'level of development' and income level. For those reasons, we kept the productspecific growth at the world average to take into account and attenuate those effects.

\subsection{Steps 2 and 3: The hybrid MR-SUT and hybrid MRIO model}

The core of the supply chain model is a MRIO model (Miller and Blair 2009). The MRIO model was built from the EXIOBASE multiregional supply-and-use table (MR-SUT) v2.2.0 (Wood et al. 2014). The reference year is 2007, the unit is million EUR, the 48 countries and regions were aggregated into 20 world regions, and the number of commodities and industries per region is 163 .

The hybrid model is built starting at the supply and use level. To the MR-SUT, one industry was added for each region: Refined cobalt production, supplying one main product: Refined cobalt, as shown in Fig. 1. Regional and sector-specific use of cobalt is estimated for 2007 using balancing algorithms and regional estimates provided by the Cobalt Development Institute and the United States Geological Survey (USGS) to match the global demand and global use pattern for cobalt. For more details regarding the procedure, we refer to section S1-4.1.1 in the Additional file 1. Use of cobalt is denoted at the intersection between the domestic refined cobalt product and the domestic cobalt using industries. And supply of cobalt is denoted on the diagonal as each producer of refined cobalt supplies its total amount of cobalt to the domestic markets. We did not determine any trade pattern for cobalt, since we are only interested in the global demand for cobalt and a matching level of supply.

To avoid double counting, background economic data need to be corrected by the amount of disaggregated production happening in the foreground using cobalt price information and inputs to cobalt production shall also be taken out from the background. Here, this is however not done for three reasons: (1) the main issue being that the SUT structure does not match perfectly the estimated use of cobalt. For example, certain industries that we know are using cobalt, do not require any 'Other non-ferrous metal' in the SUT, and hence the cobalt flow cannot be disaggregated. (2) Estimating the price of a single commodity flow is difficult: price information that can be found for refined cobalt comes as market price, which is different than the valuation of the SUT in basic prices. (3) The global value of refined cobalt represents only about $2.5 \%$ of the global value of the 'Other non-ferrous metal' sectors, and hence, the error introduced by the hybridization is very small.

A detailed description of the hybridization is contained in section S1-4.3 in the Additional file 1 .

\subsection{Step 4: Extraction model}

A linear program is applied to determine which mines will be exploited to supply the metals. It aims at minimizing the global mining risk of supplying metal. We define the mining risk as being the complement of the IAI provided by the Fraser Institute 
(Cervantes et al. 2014), which measure the attractiveness of a jurisdiction for mining companies. The core equations of the model are shown below.

$$
\begin{aligned}
& \text { minimize: } \sum_{m} C_{m}^{T} \cdot P_{m} \quad \forall m \in M \\
& \text { subject to: } \sum_{m} G_{m} \cdot P_{m}=D \quad \forall m \in M \\
& P_{m}>0 \quad \forall m \in M \\
& P_{m} \leq L_{m} \quad \forall m \in M
\end{aligned}
$$

where $M$ is the number of mine types, $C_{m}$ is a column vector representing the mining risk of mine type $m$ and its length equals the number of regions. $P_{m}$ is the mine production vector determined by the linear program. It gives the amount of ore extracted in mine type $m$ in the different regions and it has the same length as $C . G_{m}$ is the ore grades matrix of mine type $m$. It gives the average ore grade of the different metals (cobalt, copper, and nickel in our case) in the ore of mine type $m$ in the different regions and has dimension number of metals studied times the number of regions. $D$ represents the demand of the different metals that need to be mined. The last two equations set the bounds for the production vector: it has to be positive and should be lower or equal to the mining capacity $L_{m}$ that is a vector of the maximum amount of ore that can be extracted from mine type $m$ in the different regions. Additional file 2 provides the values for all parameters that are used in this work.

We are interested in assessing the future supply of cobalt, which is mostly extracted as by-product of copper and nickel mining. To reflect this by-product nature of cobalt, the model shown in equation 1 is solved by only considering copper and nickel demand. The obtained output vector $P$ is then multiplied with the cobalt grade of the different mines to determine the amount of cobalt that can be supplied. The resulting cobalt output is compared with cobalt demand. An alternative scenario would be to say that in the future, more emphasis will be put on meeting cobalt demand upfront. In that case, cobalt demand enters the linear program along with copper and nickel demand.

It is worth noting that average ore grades also influence the cost of extraction: If the ore grade of two mines mining only copper differs by a factor of ten but both mines show the same cost for extracting one ton of ore, the model will choose the one with higher grade since it can meet the copper demand 10 times 'less risky' than the low grade mine.

\subsection{Step 5: Cobalt, copper, and nickel resources and the capacity constraint}

The only operating mine with cobalt as main product is the Bou Azzer mine in Morocco. Therefore, cobalt supply is highly dependent on demand for nickel and copper, as these metals represent the main revenue streams for the mining company exploiting the deposit. This by-product nature couples the amount of cobalt that can be extracted to the demand for copper and nickel and might lead to imbalances between supply and demand. To model resources of copper, nickel, and cobalt, seven types of deposits/mines were defined: deposit that consists of only cobalt, copper or nickel, the ones that have two co-products cobalt-copper, cobalt-nickel, and copper-nickel, and the deposits that allow extraction of the three metals together.

The assessment of resources for those mine types is performed using the extensive data gathered by Mudd and Jowitt (2014) and Mudd et al (2013), which consists 
of detailed information on all deposits, being currently exploited or not, that contain nickel and copper, respectively (Mudd and Jowitt 2014; Mudd et al. 2013). The two databases should overlap when copper and nickel are both present, however, the names and deposit sizes do not always correspond between the two datasets. In case of conflict, we use the information from the nickel database as it contains more recent data. The mines/ deposits in the databases are split into the seven groups defined above. The amount of each of the three metals in each deposit is determined by the reported amount of ore and the ore grade of the different metals in presence.

Data gathered at the deposit/mine level in each countries are aggregated under the regions defined by the MRIO model and average concentrations for each metal are calculated in each regions for each type of mine. This inventory allows us to build the grade matrices for each mine type $m, G_{m}$, which give the amount of metal that can be extracted per $\mathrm{kg}$ of ore mined in each region and the reserves in ore in each type of mine $m$ in each region, $R_{m}$.

Each year, resource depletion is determined by subtracting the mine production of the previous year from the reserves. New mine capacity is installed following some simple rules. First, each year, each mine type in each region increases its capacity by $3 \%$. Furthermore, if the capacity utilization rate of a mine is higher than $80 \%$ and the mine has more than 20 years of operating time left at current capacity, then this mine is allowed to increase capacity by $20 \%$. Finally, we make sure that the mining capacity cannot be bigger than the remaining ore reserves.

\section{Results}

\subsection{World cobalt demand}

For the basic growth scenario, global annual cobalt demand increases from $50 \mathrm{kt} / \mathrm{yr}$ in 2007 to $110 \mathrm{kt} / \mathrm{y}$ in 2030 and $190 \mathrm{kt} / \mathrm{yr}$ in 2050, which is a roughly fourfold increase over the modeling period (Fig. 2). According to that scenario, the Chinese economy will remain the largest cobalt consumer and its share in the global cobalt consumption will increase from about $20 \%$ in 2007 to about $35 \%$ in 2060. As constant technology was assumed, cobalt demand scales proportional to GDP growth. Other economic regions like Africa or Indonesia will experience annual growth rates of up to eight and $6.5 \%$ in

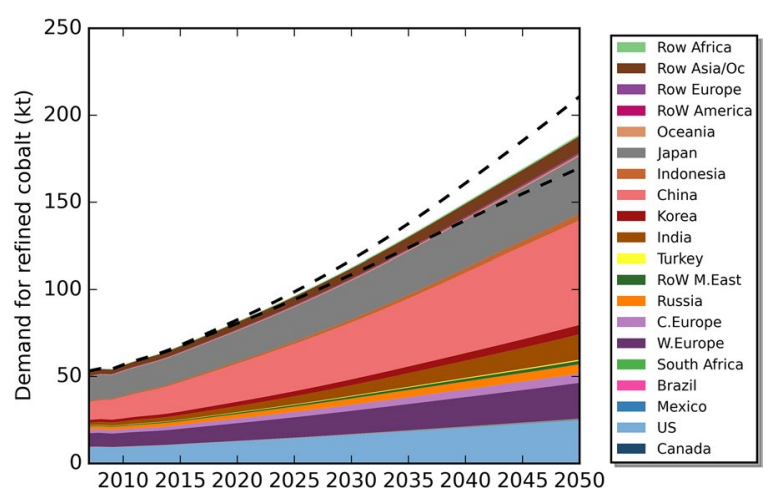

Fig. 2 Economy-wide demand for cobalt, by region, for the baseline scenario (sector-specific weighted economic growth and constant technology). Black-dashed lines show the global cobalt demand under high and low economy growth (scenarios $5 a$ and $5 b$ ) 
2010, but with the A-matrix we used, their cobalt demand will be mostly satisfied by imports of cobalt-containing products. Cumulative cobalt demand in ore that needs to be extracted for the period 2007-2050 amount to about 6300 ktons, which is about $40 \%$ of the estimated total cobalt reserves of $16 \mathrm{Mt}$ that are known and recoverable, mostly from copper and nickel mines (Mudd et al. 2013).

\subsection{Projections of future supply of cobalt, copper, and nickel}

We present results for only a selection of the most interesting scenarios, the complete set of figures and results for all scenarios can be found in Additional file 3. While there is enough known cobalt in the ground to meet demand until 2050 at least, a significant share of it is likely to come from politically instable regions, such as the Democratic Republic of the Congo, which increases the supply risk of cobalt (Fig. 3).

According to the solution of the linear program for metal supply for scenario 1a, RoW Africa, of which the Democratic Republic of the Congo is a part, supplies about as much cobalt as all other world regions together (Fig. 3 left). In this scenario, there is ample supply of cobalt as unconstrained by-product from copper and nickel mining for the years after 2015, which means that not all by-products from copper and nickel mining have to undergo Co-recovery. If the mining output solution is constrained to exactly meet cobalt demand (Fig. 3 middle), the contribution of RoW America to global cobalt supply shifts

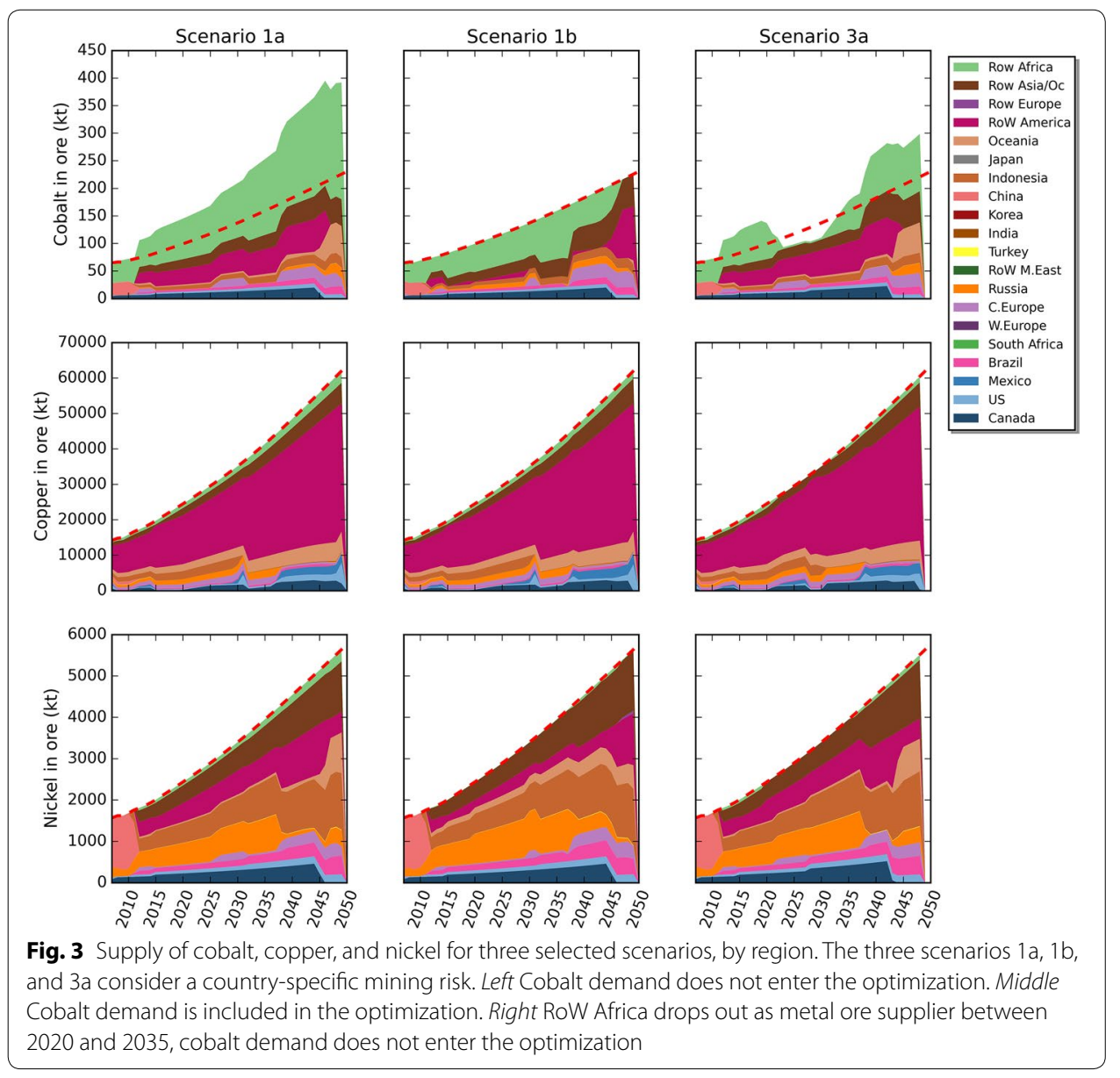


towards the end of the modeling period, and RoW Africa and RoW Asia become the largest suppliers for 2015-2045.

A drop-out of one major cobalt supplier, here RoW Africa, would lead to a supply shortage of cobalt of about $20 \%$ of global demand, provided the mining mix in other world regions did not change or previously unused tailings from $\mathrm{Co}$ and $\mathrm{Ni}$ mining were not used to produce cobalt (Fig. 3 right).

While the contributions of the different regions to global cobalt supply change significantly between the three scenarios, there is not much change in the regional pattern for $\mathrm{Cu}$ and $\mathrm{Ni}$ supply. $\mathrm{Cu}$ supply is dominated by RoW America, especially from Chile, and Ni supply is split rather evenly across RoW Asia, RoW America, Indonesia, Russia, and others. The drop-out of RoW Africa in scenario $3 \mathrm{a}$ is hardly noticeable in the $\mathrm{Cu}$ supply mix.

Cobalt is a typical accompanying metal. Future cobalt supply will be almost entirely met from the by-products of copper, nickel, or copper-nickel mines. More than $90 \%$ of the cobalt will come from cobalt-copper and cobalt-nickel mines, while a fraction of 5-10\% comes from cobalt-copper-nickel mines (Fig. 4).

While the cobalt-nickel and cobalt-copper-nickel mines will account for 30-60 \% of global nickel supply in the different scenarios, the mines with co-production of metals play almost no role in global copper supply. In Fig. 4, copper and nickel supply always meets demand because during the entire modeling time there is always sufficient supply from mines which have copper and nickel as their respective main product.

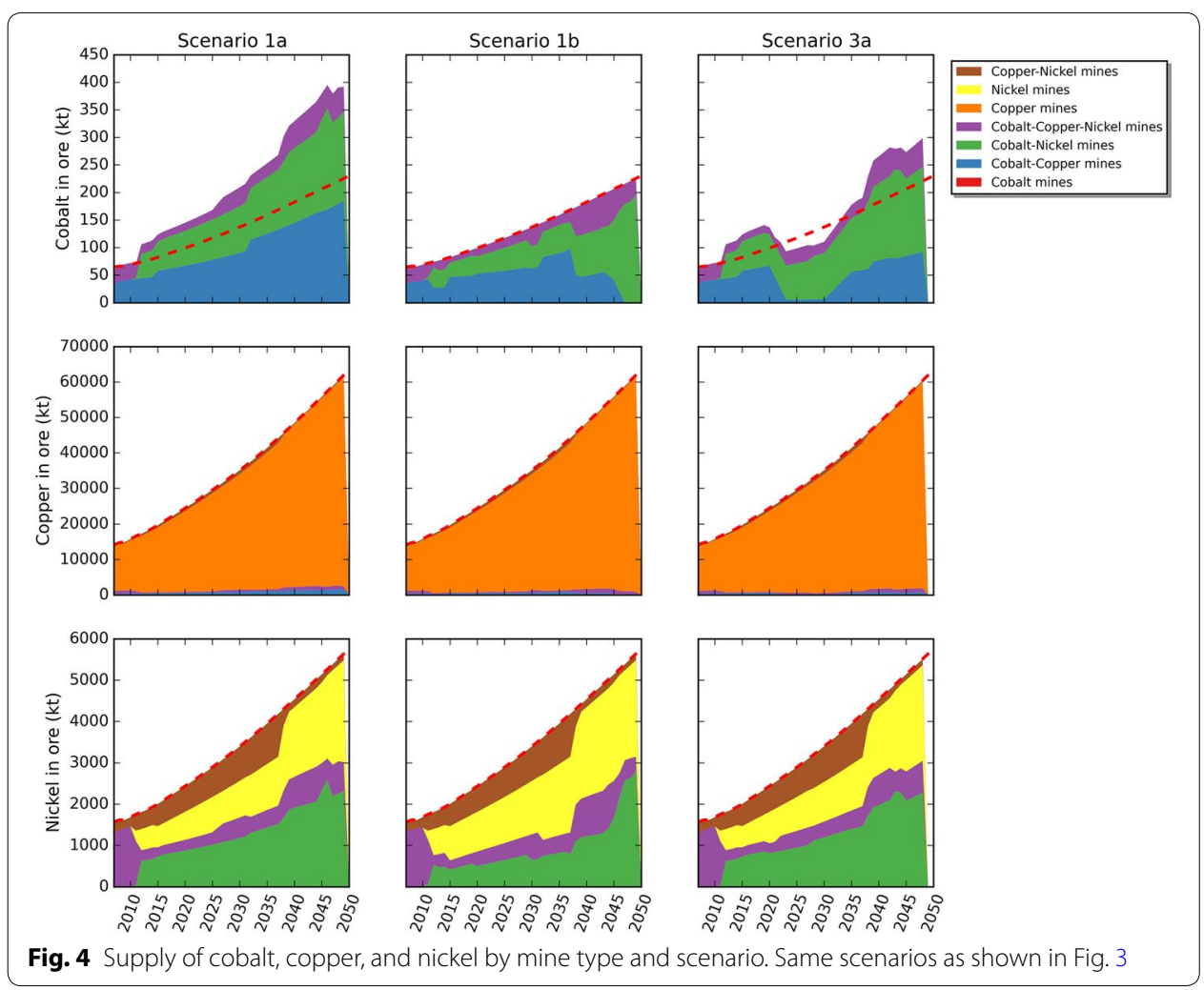




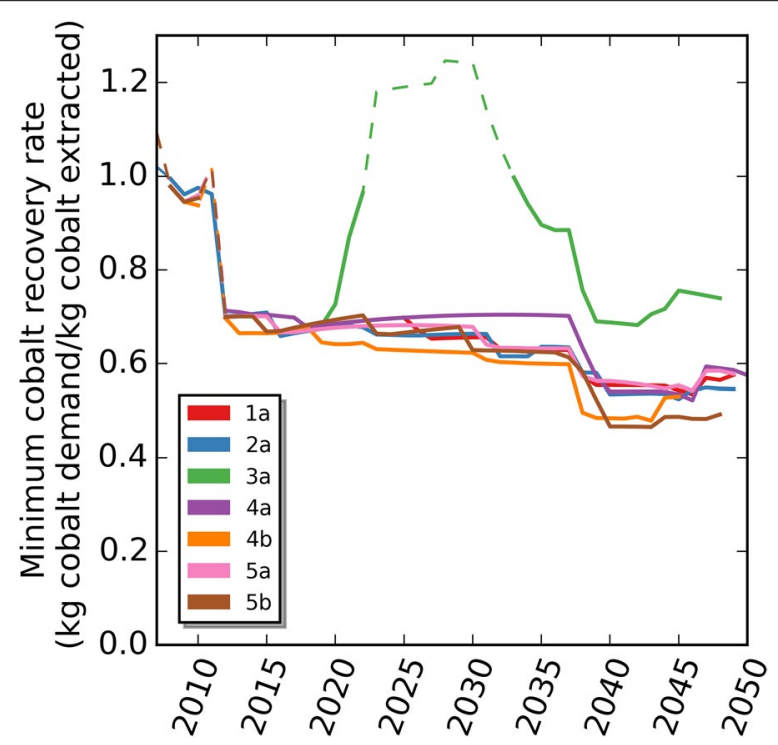

Fig. 5 Minimum cobalt recovery rate from by-products of copper and nickel mining to match cobalt demand in the scenarios where Cobalt supply is not part of the optimization routine. Dashed lines show when cobalt supply does not allow to match demand

In the scenarios where cobalt supply is not part of the optimization routine, only a fraction of the cobalt needs to be recovered from the accompanying metals of copper and nickel mining. This fraction lies around $60 \%$ for most of the modeling period (Fig. 5), and it is slowly declining, which is because cobalt-rich mines tend to be located in regions with higher mining risk, which are exploited in later years. Mudd et al. estimate that about $67 \%$ of the Co contained in the deposits with reliable data can be economically recovered (Mudd et al. 2013), which would mean that in our demand scenarios 1a, 2a, and 3a, all cobalt-containing by-product fractions would have to undergo cobalt recovery. Between 2046 and 2050, depending on the scenario, there is not enough copper resources left to justify the required capacity increase to match copper demand,

Table 3 Comparison of cobalt consumption for the world

\begin{tabular}{|c|c|c|c|}
\hline \multirow[b]{2}{*}{ Yearไref } & \multicolumn{2}{|c|}{ World refinery production (tons cobalt) } & \multirow{2}{*}{$\begin{array}{l}\text { World cobalt demand } \\
\text { growth (\%/year) } \\
\text { This work }\end{array}$} \\
\hline & USGS & This work & \\
\hline 2007 & 53,300 & 53,163 & - \\
\hline 2008 & 57,600 & 54,511 & 2.53 \\
\hline 2009 & 61,800 & 54,263 & -0.45 \\
\hline 2010 & 79,500 & 56,709 & 4.51 \\
\hline 2011 & 82,400 & 58,898 & 3.86 \\
\hline 2012 & 77,900 & 60,827 & 3.27 \\
\hline 2013 & - & 62,773 & 3.20 \\
\hline 2014 & - & 65,059 & 3.64 \\
\hline 2015 & - & 67,706 & 4.07 \\
\hline 2016 & - & 70,450 & 4.05 \\
\hline 2017 & - & 73,207 & 3.91 \\
\hline 2018 & - & 75,972 & 3.78 \\
\hline
\end{tabular}


and the model stops. For scenario $4 \mathrm{~b}$, in which the world economy gradually becomes more copper-intensive, this happens already in 2046 (see Additional file 3).

Dashed lines in Fig. 5 indicate supply shortages because the determined 'low risk' extraction pattern does not contain enough Co in the extracted ore to match global demand. However, from the mine capacity plot for scenario 3a (in Additional file 3), we can see that even in the period of shortage of cobalt supply, the installed mining capacity can provide enough cobalt to match demand. That means that there is enough capacity to rearrange the extraction pattern to match global demand, albeit at higher mining risk.

\section{Discussion}

\subsection{Comparison of MRIO-scenario with the actual development for 2007-2012}

Table 3 shows the world refinery production figures compiled by the USGS and from our own model calculations (USGS 2014). It shows that the hybrid-MRIO seems to underestimate the projection of future cobalt demand when compared to reported values by the USGS.

Furthermore, a brochure containing a cobalt market forecasting report by Roskill presents a growth estimate of more than $6 \%$ per year for cobalt demand worldwide up to 2018. The authors of this brochure also expect the cobalt demand to reach over 11,000 tons/year in 2018 (Roskill 2014), whereas our base scenario only estimates a demand around 76,000 tons/year. Comparing our results with both the USGS and Roskill's numbers leads to the same conclusion that our projection for cobalt demand may underestimate growth in the near future, and the depletion of known resources might proceed event faster than we anticipate. A main reason for the accelerated use of cobalt could be its increasing application in new technologies, as pointed out in the introduction. Accelerated growth could be reproduced by the MRIO model by adjusting the coefficients of the A-matrix, as demonstrated by Leontief and Duchin, for example (Leontief and Duchin 1986).

\subsection{Cobalt as a by-product of copper and nickel mining}

Cobalt supply is dependent on sufficiently high copper and nickel demand. Our scenario calculations show that in a setting where cobalt supply is of no concern, the extraction pattern with minimal global political risk will lead to ample supply of cobalt in the byproducts of copper and nickel mining. If major resources like the ones in the Democratic Republic of the Congo seize to supply the world markets due to political unrest, however, this is likely to affect copper, nickel, and cobalt supply alike and new supply patterns with potentially higher political and investment risk will have to be found to ensure that demand for these three metals can be met. While we could not find evidence for problems with cobalt supply in the next three decades, mainly due to corresponding high growth in copper and nickel demand in our scenarios, this may not be the case for accelerated cobalt use, for example, due to a massive upscaling of the production of cobalt-containing magnets or lithium-ion batteries. The future supply of special metals requires close monitoring of demand trends, a comprehensive assessment of mineral resources and refined modeling techniques to generate scenarios for metal supply as basis for investment and resource policy. 


\subsection{Limits of the demand model}

EXIOBASE is the only one of the available MRIO models that contains separate sectors for copper and nickel mining; only cobalt demand had to be disaggregated from other nonferrous metals. Since all three studied metals are traded on global markets, their prices can be expected to vary across narrow ranges only and we therefore believe that the use of a monetary IO model as basis for modeling physical metal demand can be justified. The larger challenge lies in the creation of meaningful scenarios for the MRIO A-matrix and final demand. Our simple attempt shall give a first impression of possible future cobalt demand under the assumption that the present structure of the world economy is preserved. Our estimate for final demand could be refined using sector-specific income elasticities. Scenarios for the future A-matrix are relevant for a very wide range of applications, not only for our study. We argue that there should be a systematic, transparent, and inclusive effort by the IO community to generate scenarios for future MRIO tables, including data generated by integrated assessment models and studies of the possible efficiency and material requirements of future technology. This development is already ongoing, and first results include the THEMIS model for renewable energy supply (Hertwich et al. 2015) and the scenario work on climate change mitigation by Koning et al. (2015). Scenarios for future trade patterns, which enter the multiregional A-matrix, can be determined using the gravity model of trade (Tinbergen 1962) or, to determine trade patterns that follow a certain objective, the world trade model (Duchin et al. 2015; Duchin 2005; Strømman and Duchin 2006; Duchin and Stephen 2015).

Better data on the share of cobalt in the nonferrous metal consumption of different economic sectors are needed to produce more trustworthy demand estimates. Since this information is not part of macroeconomic statistics, it could be estimated using process inventory databases like ecoinvent (www.ecoivent.org), the bilateral flows of cobalt embedded in the different commodity groups determined by Nansai et al. (2014), and the end-use sector split estimated by Harper et al. (2012). As resource scarcity and material criticality become more established on the political agenda, more detailed statistics on inter-industrial metal use may become compulsory in the future, as it is already the case for the use of potential conflict minerals in the US (Securities and Exchange Commission 2012).

\subsection{Limits of the resource supply model}

We used an aggregated representation of copper, nickel, and cobalt resources with 20 regions and seven resource types to determine regional patterns of resource extractions. More sophisticated and site-specific extraction models, like the one developed by Northey et al. can give a more detailed picture and may contain a more realistic and site-specific representation of capacity extension and the development of new mining projects (Northey et al. 2014). It would also allow us to take into account the cut-off grade to determine the economically recoverable amount of resources. This is particularly important for cobalt as deposits with higher grade in copper or nickel, which would probably be exploited first, do not necessarily have high cobalt grade at the same time, therefore what can be true at an aggregated level might not be the same at the deposit scale. Investment and supply risks have a site-specific component, too. They not only depend on the political climate of the hosting country but also on how the operator 
interferes with local ecosystems and how local communities react to pollution, land use change, or relocation of people. A better index taking into account country and site-specific considerations could be therefore developed, which could also include the mineralogy of the deposit and the associated environmental risk. Examples for environmental risks include the extraction of radioactive by-products (thorium in case of Dysprosium) and the arsenide nature of ores where cobalt is the main metal (Elshkaki and Graedel 2014; Mudd et al. 2013).

\subsection{Scenarios for cobalt trade}

Next to the location of cobalt-producing mines, the trade pattern of cobalt, which is outside the scope of this work, is another determiner of the global cobalt supply chains and the supply risk of individual countries. What determines trade relationships? Srivastava et al. concluded that political instability negatively impacts the amount of exports of a country, and that trade flows are especially large between countries with colonial relations in the past (Srivastava and Green 1986). Morrow et al. found that democracy and common geopolitical interests increase trade, but strategic alliances not necessarily do so. Pollins argues in the same way by saying that trade is significantly influenced by broader political relations (Morrow et al. 1998, 1999; Pollins 1989). More recently, Umana Dajud classified the political proximity of countries according to the correlation of their votes in the UN, differences in forms of government, and ideological distance of citizens, and found that political differences impact trade relations (Umana Dajud 2013). Another important aspect is the increasing willingness of the international community to stop the protracting effect of specialty metal ore export on regional conflicts, for example, the export of tantalum-containing minerals from the Democratic Republic of the Congo (Moran et al. 2014), which may alter global trade pattern.

Future trade modeling needs to bridge the gap between these qualitative findings and their application in quantitative trade models such as the gravity and the world trade models (Duchin et al. 2015; Duchin 2005; Strømman and Duchin 2006; Duchin and Stephen 2015).

Currently, our model does not contain the refining stage of cobalt because we believe the location of refining to be of secondary importance, as refiners are much easier to relocate and expand than mines. Therefore, in our model, we did not consider any restrictions or risks associated with the trade of both ore and refined cobalt.

\subsection{Recycling and dynamic modeling of the use phase of cobalt}

Recycling is central to decoupling resource demand from economic development in regions with mature in-use stocks. With the high end-of-life recycling rate of cobalt [68 \% were reported for the US (Graedel et al. 2011)] and because in-use stocks of cobalt have been growing continuously, one can expect rising amounts of Co-containing scrap in the future. Comprehensive long-term scenarios for metal cycles need to address recycling and therefore need to include dynamic stock models not only for the mineral resources of cobalt, but also for the use phase of cobalt. The combination of dynamic stock models and IO models has been demonstrated already (Nakamura et al. 2014; Kagawa et al. 2015), and it was applied in an MRIO context by Hertwich et al. to estimate the turnover rates of energy installations (Hertwich 2015). The combination of 
dynamic material stock models with input-output models with a by-product-technology construct, which would allow researchers to study how secondary materials can replace primary production, has to our knowledge not been attempted yet.

\title{
5 Conclusion
}

Estimating future resource depletion and its impact on the economy in different world regions is a complicated endeavor with uncertain results. Rather than trying to be complete in our assessment, we presented several elements that could eventually become part of a very comprehensive analysis of future material criticality. The elements we included are the global multiregional long-term scope, the consideration of both factor endowments (mineral resources) and mining risk, the decision of actors to expand or maintain production capacity, the coupling between main and accompanying metals, and the consequences of possible drop-outs of major suppliers on global supply chains. We showed that already with a stylized approach as used here, one can quantify the impact of economic growth and supply chain disruptions on resource depletion. Moreover, we extended existing methodology by combining MRIO with dynamic stock models of metal resources and by incorporating mining risk into a resources depletion model. These extensions may be relevant for applications in a different context.

\section{Additional files}

Additional file 1: Additional file that contains the details regarding the model and the MRIO framework used (aggregation of products and regions) and that also contains some additional results.

Additional file 2: Additional file provinding the set of input data used for the hybridation of the MRIO, economic growth and the extraction model.

Additional file 3: Additional file providing the complete set of figures and results for all scenarios as defined in table 2.

\begin{abstract}
Abbreviations
IAI: investment attractiveness index; LCA: life cycle assessment; MRIO: multi-regional input-output; MR-SUT: multiregional supply-and-use table; RoW: Rest of the World; SI: supplementary information; SUT: supply and use tables; USGS: United States geological survey.
\end{abstract}

\section{Authors' contributions}

SP designed the research and built the MRIO model from the CREEA MR-SUT. AT collected the foreground data and built the hybrid model, the linear program, and the dynamic stock model, and performed the analysis. Both AT and SP wrote the paper. Both authors read and approved the final manuscript.

Author details

${ }^{1}$ Industrial Ecology Programme, Department of Energy and Process Engineering, Norwegian University of Science and Technology, 7491 Trondheim, Norway. ${ }^{2}$ Faculty of Environment and Natural Resources, University of Freiburg, Tennenbacher Str. 4, 79106 Freiburg, Germany.

\section{Acknowledgements}

The work of SP was funded by the European Commission under the DESIRE Project (Grant number 308552). The research was conducted without involvement of the funding source. The authors thank Richard Wood for his help with parsing the CREEA MR-SUT and for advices regarding hybridization of the MRIO, Guillaume Majeau-Bettez for advice and programming assistance on the treatment of exclusive by-products in a multiregional MR-SUT, and Yasushi Kondo for making us aware of the economic freedom index of the Fraser Institute. AT thanks Richard Wood for the time given to complete this side project. The authors thank the journal's editor and two anonymous reviewers for their constructive comments.

\section{Competing interests}

The authors declare that they have no competing interests. 


\section{References}

Busch J, Steinberger JK, Dawson DA, Purnell P, Roelich KE (2014) Managing critical materials with a technology- specific stocks and flows model. Environ Sci Technol 48(2):1298-1305

Cervantes M, Green KP, Wilson A (2014) Survey of Mining Companies: 2013/2014. http://www.fraserinstitute.org/researchnews/display.aspx?id=20902

Duchin $\mathrm{F}$ (2005) A world trade model based on comparative advantage with $\mathrm{m}$ regions, $\mathrm{n}$ goods, and $\mathrm{k}$ factors. Econ Syst Res 17(2):141-162. http://www.tandfonline.com/doi/abs/10.1080/09535310500114903\nhttp://www. tandfonline.com/doi/abs/10.1080/09535310500114903\#.Us1XbbTn6Solnhttp://www.tandfonline.com/doi/ $\mathrm{pdf} / 10.1080 / 09535310500114903$

Duchin F, Stephen SH (2015) Sustainable use of global resources: combining multiregional input-output analysis with a world trade model for evaluating scenarios. part 2: implementation. J Ind Ecol 00:1-9

Duchin F, Stephen SH, Strømman AH (2015) Sustainable use of global resources: combining multiregional input-output analysis with a world trade model for evaluating scenarios. part 1: conceptual framework. J Ind Ecol 00:1-8

Elshkaki A, Graedel TE (2013) Dynamic analysis of the global metals flows and stocks in electricity generation technologies. J Clean Prod 59:260-273

Elshkaki A, Graedel TE (2014) Dysprosium, the balance problem, and wind power technology. Appl Energy 136:548-559

EU DESIRE Project. 2013. EU DESIRE Project

EuropeanCommission (2010) Critical raw materials for the EU, report of the Ad hoc working group on defining critical raw materials. Eucom 39(July):1-84

Frenzel M, Tolosana-Delgado R, Gutzmer J (2015) Assessing the supply potential of high-tech metals - a general method. Res Policy 46:45-58. http://linkinghub.elsevier.com/retrieve/pii/S0301420715000781

Gerling JP, Wellmer F, Gerling JP (2004) Raw material availability — with a focus on fossil energy resources. World Min— Surf Undergr 56(4):254-262

Gibon T, Wood R, Arvesen A, Bergesen JD, Suh S, Hertwich EG (2015) A methodology for integrated, multiregional life cycle assessment scenarios under large-scale technological change. Environ Sci Technol 49(18):11218-11226. http://pubs.acs.org/doi/10.1021/acs.est.5b01558

Graedel TE, Allwood J, Birat JP, Buchert M, Hagelüken C, Reck BK, Sibley SF, Sonnemann G (2011) What do we know about metal recycling rates? J Ind Ecol 15(3):355-366. http://doi.wiley.com/10.1111/j.1530-9290.2011.00342.x

Graedel TE, Reck BK (2015) Six years of criticality assessments: What have we learned so far? J Ind Ecol 00(0):n/a-n/a. http://doi.wiley.com/10.1111/jiec.12305

Graedel TE, Barr R, Chandler C, Chase T, Choi J, Christoffersen L, Friedlander E et al (2012) Methodology of metal criticality determination. Environ Sci Technol 46(2):1063-1070

Greenfield A, Graedel TE (2013) The omnivorous diet of modern technology. Resour Conserv Recycl 74:1-7

Harper EM, Kavlak G, Graedel TE (2012) Tracking the metal of the goblins: cobalt's cycle of use. Environ Sci Technol 46(2):1079-1086

Hatayama H, Daigo I, Matsuno Y, Adachi Y (2010) Outlook of the world steel cycle based on the stock and flow dynamics. Environ Sci Technol 44(16):6457-6463

Hawkins T, Hendrickson C, Higgins C, Matthews HS, Suh S (2007) A mixed-unit input-output model for environmental life-cycle assessment and material flow analysis. Environ Sci Technol 41(3):1024-1031

Hertwich EG, Gibon T, Bouman EA, Arvesen A, Suh S, Heath GA, Bergesen JD, Ramirez A, Vega MI, Shi L (2015) Integrated life-cycle assessment of electricity-supply scenarios confirms global environmental benefit of low-carbon technologies. Proc Natl Acad Sci USA 112(20):6277-6282. http://www.pnas.org/lookup/doi/10.1073/pnas.1312753111

IPCC (2014) Mitigation of climate change: the working group III (WGIII) contribution to the Fifth Assessment Report on mitigation of climate change. Switzerland, Geneva

Kagawa S, Nakamura S, Kondo Y, Matsubae K, Nagasaka T (2015) Forecasting replacement demand of durable goods and the induced secondary material flows. J Ind Ecol 19(1):10-19

Knoeri C, Wäger PA, Stamp A, Althaus HJ, Weil M (2013) Towards a dynamic assessment of raw materials criticality: linking agent-based demand — with material flow supply modelling approaches. Sci Total Environ 461-462:808-812

de Koning A, Huppes G, Deetman S, Tukker A (2015) Scenarios for a $2^{\circ} \mathrm{C}$ world: a trade-linked input-output model with high sector detail. Climate Policy 3062(December):1-17. http://www.tandfonline.com/doi/abs/10.1080/14693062.2 014.999224

LeontiefW, Duchin F (1986) The Future Impact of Automation on Workers. Oxford University Press, New York

Liu G, Bangs CE, Müller DB (2012) Stock dynamics and emission pathways of the global aluminium cycle. Nat Clim Change 2(10):1-5

Løvik AN, Restrepo E, Müller DB (2015) The global anthropogenic Gallium system: determinants of demand, supply and efficiency improvements. Environ Sci Technol 49(9):5704-5712. http://www.ncbi.nlm.nih.gov/pubmed/25884251

Miller RE, Blair PD (2009). Input-Output Analysis-Foundations and Extensions. 2nd ed. Cambridge University Press

Moran D, McBain D, Kanemoto K, Lenzen M, Geschke A (2014) Global supply chains of coltan a hybrid life cycle assessment study using a social indicator. J Ind Ecol 00:1-9

Morrow JD, Siverson RM, Tabares TE, Stanford JDM (1998) The political determinants of internation trade: the major powers. Am Political Sci Rev 92(3):649-661

Morrow JD, Siverson RM, Tabares TE (1999) Correction to "the political determinants of international trade". Am Political Sci Rev 93(4):931-933

Mudd G, Weng Z, Jowitt S, Turnbull ID, Graedel TE (2013b) Quantifying the recoverable resources of by-product metals: the case of cobalt. Ore Geol Rev 55(C):87-98. http://dx.doi.org/10.1016/j.oregeorev.2013.04.010

Mudd G, Jowitt S (2014) A detailed assessment of global Ni resource trends and endowments. Econ Geol 109:1813-1841

Mudd G, Weng Z, Jowitt S (2013) A detailed assessment of global Cu resource trends and endowments. Econ Geol 108:1163-1183

Nakajima K, Ohno H, Kondo Y, Matsubae K, Takeda O, Miki T, Nakamura S, Nagasaka T (2013) Simultaneous material flow analysis of nickel, chromium, and molybdenum used in alloy steel by means of input-output analysis. Environ Sci Technol 47(9):4653-4660 
Nakamura S, Murakami S, Nakajima K, Nagasaka T (2008) Hybrid input-output approach to metal production and its application to the introduction of lead-free solders. Environ Sci Technol 42(10):3843-3848

Nakamura S, Kondo Y, Kagawa S, Matsubae K, Nakajima K, Nagasaka T (2014) MaTrace: tracing the fate of materials over time and across products in open-loop recycling. Environ Sci Technol 48(13):7207-7214

Nansai K, Nakajima K, Kagawa S, Kondo Y, Suh S, Shigetomi Y, Oshita Y (2014) Global flows of critical metals necessary for low-carbon technologies: the case of neodymium, cobalt, and platinum. Environ Sci Technol 48(3):1391-1400

Northey S, Mohr S, Mudd G, Weng Z, Giurco D (2014) Modelling future copper ore grade decline based on a detailed assessment of copper resources and mining. Resour Conserv Recycl 83:190-201. doi:10.1016/j. resconrec.2013.10.005

Nuss P, Harper EM, Nassar NT, Reck BK, Graedel TE (2014) Criticality of iron and its principal alloying elements. Environ Sci Technol 48(7):4171-4177

OECD (2015) GDP long-term forecast. OECD. https://data.oecd.org/gdp/gdp-long-term-forecast.htm. Accessed November 3, 2015

Ohno H, Matsubae K, Nakajima K, Nakamura S, Nagasaka T (2014) Unintentional flow of alloying elements in steel during recycling of end-of-life vehicles. J Ind Ecol 18(2):242-253

Pauliuk S, Hertwich EG (2015) Prospective models of society's future metabolism — what industrial ecology has to contribute. In: Roland C, Angela D (ed) Taking stock of industrial ecology. Springer, Dordrecht, In press

Pauliuk S, Milford RL, Müller DB, Allwood J (2013) The steel scrap age. Environ Sci Technol 47(7):3448-3454

Peiró LT, Méndez GV, Ayres RU (2013) Material flow analysis of scarce metals: sources, functions, end-uses and aspects for future supply. Environ Sci Technol 47(6):2939-2947

Pollins BM (1989) Conflict, cooperation and commerce: the effect of international political interactions on bilateral trade flows. Am J Polit Sci 33(3):737-761

Prior T, Giurco D, Mudd G, Mason L, Behrisch J (2012) Resource depletion, peak minerals and the implications for sustainable resource management. Glob Environ Change 22(3):577-587

Roelich KE, Dawson DA, Purnell P, Knoeri C, Revell R, Busch J, Steinberger JK (2014) Assessing the dynamic material criticality of infrastructure transitions: a case of low carbon electricity. Appl Energy 123:378-386

Roskill (2014) A 2014 Roskill report Cobalt : Market Outlook to 201. Cobalt

Securities and Exchange Commission (2012) 17 CFR Parts 240 and 249b. http://www.sec.gov/rules/final/2012/34-67716. pdf

Seddon M (2001) The cobalt market—current volatility versus future stability? Appl Earth Sci 110(2):71-74

Shigetomi Y, Nansai K, Kagawa S, Tohno S (2015) Trends in Japanese households' critical-metals material footprints. Ecol Econ 119: 118-126. http://linkinghub.elsevier.com/retrieve/pii/S0921800915003468

Srivastava RK, Green RT (1986) Determinants of bilateral trade flows. J Bus 59(4):623-640

Strømman AH, Duchin F (2006) A world trade model with bilateral trade based on comparative advantage. Econ Syst Res 18(3):281-297. http://www.scopus.com/inward/record.url?eid=2-s2.0-33748112791\&partnerlD=40\nhttp:// pdfserve.informaworld.com/877850_751305627_755220960.pdf

Tinbergen J (1962) Shaping the World Economy; Suggestions for an International Economic Policy. Twentieth Century Fund, New York

Tukker A, Dietzenbacher E (2013) Global multiregional input-output frameworks: an introduction and outlook. Econ Syst Res 25(1):1-19. http://www.tandfonline.com/doi/abs/10.1080/09535314.2012.761179

Umana Dajud C (2013) Political Proximity and International Trade. Econ Pol 25(3):n/a-n/a

USGS (2014) Minerals Yearbook Cobalt - 2012

Wood R, Stadler K, Bulavskaya T, Lutter S, Giljum S, de Koning A, Kuenen J et al (2014) Global sustainability accountingdeveloping exiobase for multi-regional footprint analysis. Sustainability 7(1):138-163

World Bank (2015) GDP (current US\$). World Bank. http://databank.worldbank.org/data/reports.aspx? source=2\&type=m etadata\&series $=$ NY.GDP.MKTP.CD. Accessed 3 Nov 2015

Zuser A, Rechberger H (2011) Considerations of resource availability in technology development strategies: the case study of photovoltaics. Resour Conserv Recycl 56(1):56-65

\section{Submit your manuscript to a SpringerOpen ${ }^{\circ}$ journal and benefit from:}

- Convenient online submission

- Rigorous peer review

- Immediate publication on acceptance

- Open access: articles freely available online

- High visibility within the field

- Retaining the copyright to your article

Submit your next manuscript at $\mathbf{s p r i n g e r o p e n . c o m ~}$ 